\title{
Bioequivalence Study of Two Loperamide Hydrochloride 2 mg Formulations: An Open-Label, Randomized, Single-Dose, Two-Way Crossover Study in Healthy Volunteers under Fasting Conditions
}

\author{
Wen Yao Mak ${ }^{1 \natural^{*}}$, Yi Lin Lee ${ }^{14}$, Siew Siew Tan², Jia Woei Wong ${ }^{2}$, Siaw Kuen Chin², Ai Boey Lim², Ean Peng Soon², Irene Looi and Kah Hay \\ Yuen $^{2}$ \\ ${ }^{1}$ Clinical Research Centre, Hospital Seberang Jaya, Jalan Tun Hussein Onn, 13700 Seberang Jaya, Pulau Pinang, Malaysia \\ ${ }^{2}$ Attest Research Sdn Bhd, BA/BE Laboratory, Room 024, Kompleks EUREKA, Universiti Sains Malaysia, 11800 USM, Pulau Pinang, Malaysia \\ ${ }^{\natural}$ Co-authors
}

\begin{abstract}
The objective of this study was to compare the rate and extent of drug absorption of the test product (Colodium $2 \mathrm{mg}$ Capsule, Hovid Bhd.) against the reference product (Imodium ${ }^{\circledR} 2$ mg Capsule, Janssen Cilag S.A.) in twentythree healthy male volunteers under fasting condition in order to evaluate bioequivalence. A single dose of $8 \mathrm{mg}$ (4 capsules of $2 \mathrm{mg}$ each) of test and reference products were given to volunteers during two periods of the study respectively. There was a 7 day washout period between the two study periods. Blood samples were taken at pre-dose and at 13 time points up till $48 \mathrm{~h}$ post dosing. Plasma levels of loperamide were determined by liquid chromatography-tandem mass spectrometry. The plasma concentration-time data was used to estimate the pharmacokinetic parameters, namely, $\mathrm{C}_{\max }, \mathrm{T}_{\max }, \mathrm{AUC}_{0-\mathrm{t}}$ and $\mathrm{AUC}_{0-\infty}$. Analysis of variance (ANOVA) procedure was used to analyze the values of $C_{\max }, A \cup C_{0-t}, A \cup C_{0-\infty}$ and $k_{e}$ obtained from the two preparations. For the analysis of $T_{\max }$ values, the Wilcoxon Signed Rank Test for paired samples was used. In this study, the $90 \%$ confidence interval for the ratio of the $\mathrm{AUC}_{0-\mathrm{t}}, \mathrm{AUC}_{0-\infty}$ and $\mathrm{C}_{\max }$ were calculated to be between $0.8730-1.0181,0.8852-0.9891$ and $0.8023-$ 0.9559 respectively. All of the values were within the acceptable bioequivalence requirement of $0.8000-1.2500$. No drug-related adverse event was reported throughout the study. Thus, the two preparations could be concluded to be bioequivalent and interchangeable.
\end{abstract}

Keywords: Bioequivalence; Generic; Loperamide; Antidiarrheal

\section{Introduction}

Loperamide, a phenylpiperidine derivative [1], is an anti-diarrhoeal medication which acts selectively on peripheral $\mu$-opioid receptors [2]. It is widely used for acute and chronic diarrhoea. Its efficacy is also proven in treating patients with irritable bowel syndrome who suffer predominantly from diarrhea [2].

By binding to the $\mu$-opioid receptors in the gut wall, loperamide decreases peristalsis and fluid secretion, resulting in longer gastrointestinal transit time and increased absorption of fluids and electrolytes from the gastrointestinal tract [1]. This decreases the number of bowel movements and improve the consistency of the stools [2]. Loperamide has also been shown to reduce sensitivity of the rectoanal inhibitory reflex and increase internal anal sphincter tone, making it a potential candidate for treating faecal incontinence [3].

Loperamide is absorbed mainly from the gut. However, its systemic bioavailability is only about $0.3 \%$ due to significant first pass metabolism [4]. In the distribution studies in rats, loperamide has been shown to be a P-glycoprotein substrate which has a high affinity for the receptors of the longitudinal muscle layer at the gut wall. $95 \%$ of loperamide binds to plasma protein, mainly to albumin. Loperamide is metabolized mainly via oxidative $\mathrm{N}$-demethylation. It is metabolized, conjugated and excreted predominantly via the bile. The metabolic pathway is mediated by CYP3A4 and CYP2C8. In man, loperamide's half-life is about $11 \mathrm{~h} \mathrm{[4]}$.

All Malaysian citizens have access to public healthcare. The expenses are largely covered by general revenue and taxation collected by the federal government. The well-established and extensive health care services are beneficial especially to poor patients who cannot afford private healthcare services [5]. Thus, it is vital to maintain health care expenses at an affordable level to ensure that the federal government can continue to provide healthcare services to the public in the long run.

Antimotility drugs such as loperamide are the agent of choice recommended by World Gastroenterology Organization in acute and chronic diarrhea for adults to ease symptoms. It is also one of the over-the-counter drug which shows efficacy and safety as an anti-diarrheal [6]. Despite that, the innovator product's relatively high cost does not favour its wide usage. Therefore, generic product can provide a more affordable treatment alternative to healthcare providers and patients.

The aim of this study was to compare the rate and extent of drug absorption of a generic formulation of loperamide $2 \mathrm{mg}$ capsule (Colodium $2 \mathrm{mg}$ Capsule, manufactured by Hovid Bhd., Perak, Malaysia) against the reference formulation (Imodium 2 mg Capsule, manufactured by Janssen Cilag S.A., France) under fasting condition in order to evaluate bioequivalence.

*Corresponding author: Wen Yao Mak, Clinical Research Centre, Hospita Seberang Jaya, Jalan Tun Hussein Onn, 13700 Seberang Jaya, Pulau Pinang Malaysia, Tel: 04-3827333 Ext 511; Fax: 04-3902192; E-mail: makwy@crc.gov.my

Received March 21, 2016; Accepted April 21, 2016; Published April 28, 2016

Citation: Mak WY, Lee YL, Tan SS, Wong JW, Chin SK, et al. (2016) Bioequivalence Study of Two Loperamide Hydrochloride 2 mg Formulations: An Open-Label, Randomized, Single-Dose, Two-Way Crossover Study in Healthy Volunteers under Fasting Conditions. J Bioequiv Availab 8: 145-148. doi:10.4172/jbb.1000285

Copyright: (ㅇ 2016 Mak WY, et al. This is an open-access article distributed under the terms of the Creative Commons Attribution License, which permits unrestricted use, distribution, and reproduction in any medium, provided the original author and source are credited. 
Citation: Mak WY, Lee YL, Tan SS, Wong JW, Chin SK, et al. (2016) Bioequivalence Study of Two Loperamide Hydrochloride 2 mg Formulations: An Open-Label, Randomized, Single-Dose, Two-Way Crossover Study in Healthy Volunteers under Fasting Conditions. J Bioequiv Availab 8: 145-148. doi:10.4172/jbb.1000285

\section{Methods}

\section{Study protocol}

The Medical Research and Ethics Committee (MREC), Ministry of Health Malaysia approved the study protocol. All procedures were conducted in accordance to the Malaysian Good Clinical Practice (GCP) Guideline and informed consents were obtained prior to study enrolment. The clinical facility for this study was situated at the Clinical Research Centre, Seberang Jaya Hospital (Penang, Malaysia) while the bioanalytical facility was located at the BA/BE Laboratory, Universiti Sains Malaysia (Penang, Malaysia).

\section{Participants}

Healthy Malaysian male volunteers aged between 21 to 55 years old who had body mass index between 18.5 to 29.9 or within $20 \%$ of ideal body weight for height and build according to the Metropolitan Life Insurance Company Standard, were recruited at the clinical research centre by GCP-certified investigators. Clinical evaluations conducted during screening include detailed medical history, physical examination, 12 lead electrocardiogram and laboratory tests namely liver function test, renal function test, full blood count and fasting blood glucose level.

Subjects with a history or suspicion of drug dependence and/or alcohol abuse, significant clinical deviation from normal as determined by investigators, requirement of tranquilizers, sedatives or medications for chronic diseases will be excluded. Other exclusion criteria included hypersensitivity to loperamide, subjects had donated blood or participated in any bioequivalence study for the past 8 weeks, heavy smoker (i.e., more than 10 cigarettes a day), or unable to demonstrate ability to read, understand and/or comply to the study protocol or to give consent.

\section{Study design}

This was a single center, single-dose, randomized, open-label, two-way crossover study under fasting condition. In the Summary of Product Characteristics of Loperamide, it was recommended to take the capsules with liquid, irrespective of food intake [4].

The subjects were equally divided into two groups randomly; where the first group received the products in the sequence of reference-test (RT) while the second group had the sequence of test-reference (TR). There was a period of at least seven days as washout between the two phases.

All volunteers were required to fast for at least $10 \mathrm{~h}$ prior to dosing. A single dose of $8 \mathrm{mg}$ (4 capsules of $2 \mathrm{mg}$ each) of either test or the reference formulation was administered with $240 \mathrm{ml}$ of plain water under the supervision of a qualified pharmacist. Besides the water used for drug administration, participants were not allowed to drink water for one hour before and one hour after dosing. Post dosing, food was withheld for at least $4 \mathrm{~h}$. Then, standardised, calorie-counted meals were served at $4 \mathrm{~h}$ and $10 \mathrm{~h}$ after dosing while standardised snacks were given at $7 \mathrm{~h}$ and $13 \mathrm{~h}$ after dosing.

By referring to the $T_{\max }$ and $t_{1 / 2}$ of loperamide, blood samples were collected in blood collection tubes (containing sodium heparin as anticoagulant) at 0 (pre-dose), 1, 2, 3, 4, 5, 6, 7, 8, 9, 12, 16, 24 and 48 $\mathrm{h}$ after dosing. $5 \%$ deviation from the scheduled blood sampling time was allowed before being considered as protocol deviation. At the end of the $24 \mathrm{~h}$ sampling period, subjects were discharged from the clinical facility. They were required to return for blood sampling at $48 \mathrm{~h}$. A total of approximately $217 \mathrm{ml}$ of blood were taken from each subject for the entire study $(105 \mathrm{ml}$ during each phase and $7 \mathrm{ml}$ for blood chemistry analysis during screening). The collected blood samples were immediately centrifuged for $15 \mathrm{~min}$ at $3500 \mathrm{rpm}$ and the plasma samples were transferred to a separate glass tube where they were kept frozen at $-20^{\circ} \mathrm{C}$ until analysis.

The sample size was estimated using the intra-subject coefficient of variation $(\mathrm{CV})$. Based on previous bioequivalence study on loperamide capsule, the $\mathrm{CV}$ values for $\mathrm{AUC}_{0-\mathrm{t}}, \mathrm{AUC}_{\mathrm{o- \infty}}$ and $\mathrm{C}_{\max }$ ranged from approximately $18.4 \%$ to $23.2 \%$. Therefore, according to the nomogram published by Diletti et al. [7], 24 volunteers would be required for the present study in order to achieve a statistical power of $80 \%$ by assuming that the $\mu_{\mathrm{T}} / \mu_{\mathrm{R}}$ does not deviate by more than $5 \%$.

\section{Randomization and blinding}

The volunteers were randomised equally into the TR or RT group by using randomisation software. This study was an open-label trial, where the investigators and subjects were not blinded as only objective measurements (plasma concentrations) were collected and no subjective data were obtained. Nevertheless, the randomisation list was only available to the bioanalytical team after the analysis was completed.

\section{Drug analysis}

The analysis of the plasma levels of loperamide was done using a liquid chromatography-tandem mass spectrometry (LC-MSMS) in accordance with the Good Laboratory Practice. The liquid chromatography system was made up of a Agilent 1200 Series binary pump (Agilent, Waldbronn, Germany), a Agilent 1200 Series degasser (Agilent, Waldbronn, Germany), a Agilent 1200 Series thermostatted column compartment (Agilent, Waldbronn, Germany) and a Agilent 1200 Series instant pilot (Agilent, Waldbronn, Germany). Applied Biosystems API 3200 triple quadrupole mass spectrometer (Applied Biosystems/MDS SCIEX, Ontario, Canada) in positive electrospray ionization (ESI) mode was used to perform MS/MS analyses. Data acquisition and analysis were conducted using Analyst version 1.4.2 (Applied Biosystems/MDS SCIEX, Ontario, Canada).

The chromatographic separation was performed at $25^{\circ} \mathrm{C}$ using a C18 analytical column. The mobile phase was a mixture of $30 \%$ of $5 \mathrm{mM}$ ammonium acetate and $70 \%$ acetonitrile, adjusted to $\mathrm{pH} 5.0$. The separation was run isocratically at a flow rate of $0.2 \mathrm{ml} / \mathrm{min}$. The injection volume was $10 \mu \mathrm{l}$ and the samples were quantified using peak area.

The detector response for loperamide showed linearity over a concentration range of $0.08-40.00 \mathrm{ng} / \mathrm{ml}$ (correlation coefficient $\geq$ 0.99 ). The limit of quantification was set at $0.08 \mathrm{ng} / \mathrm{ml}$ while the limit of detection was set at $0.04 \mathrm{ng} / \mathrm{ml}$. The extraction recovery of loperamide was all above $80 \%$.

\section{Tolerability}

At pre-dose, $4 \mathrm{~h}, 10 \mathrm{~h}$ and $24 \mathrm{~h}$ post dose, subjects' vital signs i.e. blood pressure, pulse rate; respiratory rate and temperature were recorded. Subjects were also asked to report any discomfort or adverse events at any time during the study period.

\section{Pharmacokinetics analysis}

The plasma concentration-time data was used to estimate the pharmacokinetic parameters, namely, maximum plasma concentration $\left(\mathrm{C}_{\max }\right)$, time to reach maximum plasma concentration $\left(\mathrm{T}_{\max }\right)$, area under the plasma concentration-time curve from time zero to the last 
Citation: Mak WY, Lee YL, Tan SS, Wong JW, Chin SK, et al. (2016) Bioequivalence Study of Two Loperamide Hydrochloride 2 mg Formulations: An Open-Label, Randomized, Single-Dose, Two-Way Crossover Study in Healthy Volunteers under Fasting Conditions. J Bioequiv Availab 8: 145-148. doi:10.4172/jbb.1000285

measurable concentration $\left(\mathrm{AUC}_{0-\mathrm{t}}\right)$ and total area under the plasma concentration-time curve $\left(\mathrm{AUC}_{0-\infty}\right)$. The values of $\mathrm{C}_{\max }$ and $\mathrm{T}_{\max }$ were obtained directly from the plasma values [8]. The value $\mathrm{AUC}_{0-\infty}$ was obtained by adding the values of $\mathrm{AUC}_{0-\mathrm{t}}$ and $\mathrm{AUC}_{\mathrm{t}-\infty}$. $\mathrm{AUC}_{0-\mathrm{t}}$ was calculated by adding the area from time zero to last sampling time using the trapezoidal formula while $\mathrm{AUC}_{\mathrm{t}-\infty}$ was obtained by adding the area from time $t$ to infinity and dividing the last measurable plasma drug concentration with the elimination rate constant $\left(\mathrm{k}_{\mathrm{e}}\right)$

The $\mathrm{k}_{\mathrm{e}}$ of loperamide was estimated from the terminal slope of the individual plasma concentration-time curves after the logarithmic (ln) transformation of at least three plasma concentration values and application of linear regression [9]. The half-life $\left(t_{1 / 2}\right)$ was derived from the equation: $\mathrm{t}_{1 / 2}=\ln 2 / \mathrm{k}_{\mathrm{e}}$.

\section{Statistical analysis}

The statistical analysis was performed using the commercial software, EquivTestPK from Statistical Solution (Cork, Ireland). To distinguish effects due to subjects, periods, and treatments, analysis of variance (ANOVA) procedure was used to analyze the values of $\mathrm{C}_{m a x}, \mathrm{AUC}_{0+\mathrm{t}}, \mathrm{AUC}_{0-\infty}$ and $\mathrm{k}_{\mathrm{e}}$ obtained from the two preparations [10]. The values of $\mathrm{C}_{\max }, \mathrm{AUC}_{0-\mathrm{t}}$ and $\mathrm{AUC}_{0-\infty}$ were logarithmic transformed (natural $\log$ ) before analysis. For the analysis of $\mathrm{T}_{\max }$ values, the Wilcoxon Signed Rank Test for paired samples was used.

Bioequivalence was determined based on the $90 \%$ confidence intervals for the ratio of the $\mathrm{C}_{\max }, \mathrm{AUC}_{0-\mathrm{t}}, \mathrm{AUC}_{0-\infty}$ values of test over reference formulations. The $90 \%$ confidence intervals were calculated by using the two one-sided test procedure at the $\alpha=5 \%$ level of significance [11]. The $90 \%$ confidence interval of the ratio of $\mathrm{C}_{\max }, \mathrm{AUC}_{0-\mathrm{t}}$ and $\mathrm{AUC}_{0}$ should fall between $80.00-125.00 \%$ (transformed values) [12]. The Malaysian Guideline for Conduct of Bioavailability and Bioequivalence Studies stipulated a similar range for $\mathrm{AUC}_{0-\mathrm{t}}$ and $\mathrm{AUC}_{0-\infty}$, but allowed a wider range for $\mathrm{C}_{\max }$ when it was appropriately justified.

\section{Results}

The basic demographic characteristics of 24 subjects are as shown in Table 1.

There was one subject who withdrew from the study due to personal reasons. The remaining 23 participants successfully completed both phases of the study and the plasma samples collected were used for pharmacokinetic analysis. There was no significant deviation from the protocol arisen throughout the study.

Figure 1 showed the mean plasma loperamide concentration versus time profiles for both test and reference formulations while Table 2 showed the pharmacokinetic parameters for both formulations. As

\begin{tabular}{|l|c|c|c|c|}
\hline Variable & & $\boldsymbol{n}(\%)$ & Median (IQR) & Mean (SD) \\
\hline Age (year) & & & $26.0(10.00)$ & \\
\hline Race & & & & \\
\hline & Malay & $17(70.8)$ & & \\
\hline & Chinese & $5(20.8)$ & & \\
\hline Indian & $1(4.2)$ & & $169.1(73.61)$ \\
\hline Weight (cm) & Indonesian & $1(4.2)$ & & $70.2(11.35)$ \\
\hline $\begin{array}{l}\text { Boight (kg) } \\
\text { (kg/m²) }\end{array}$ & & & & $24.5(3.21)$ \\
\hline
\end{tabular}

Legends: $S D=S t a n d a r d$ Deviation; IQR=Interquartile Range

Table 1: Basic demographic characteristics of 24 subjects.

\begin{tabular}{|c|c|c|}
\hline $\begin{array}{c}\text { Pharmacokinetic } \\
\text { Parameters }\end{array}$ & $\begin{array}{c}\text { Test Formulation, } \\
\text { Mean (SD) }\end{array}$ & $\begin{array}{c}\text { Reference formulation, } \\
\text { Mean (SD) }\end{array}$ \\
\hline AUC $_{0-\mathrm{t}}(\mathrm{hr} . \mathrm{ng} / \mathrm{ml})$ & $23.4(9.43)$ & $24.8(9.64)$ \\
\hline $\mathrm{AUC}_{0-\infty}(\mathrm{hr} . \mathrm{ng} / \mathrm{ml})$ & $26.8(10.04)$ & $28.7(10.20)$ \\
\hline $\mathrm{C}_{\max }(\mathrm{ng} / \mathrm{ml})$ & $1.9(0.65)$ & $2.2(0.84)$ \\
\hline $\mathrm{T}_{\max }(\mathrm{hr})$ & $4.0(1.80)$ & $2.8(1.44)$ \\
\hline $\mathrm{k}_{\mathrm{e}}\left(\mathrm{hr}^{-1}\right)$ & $0.07(0.036)$ & $0.07(0.062)$ \\
\hline $\mathrm{t}_{1 / 2}(\mathrm{hr})$ & $12.5(3.87)$ & $12.5(4.22)$ \\
\hline
\end{tabular}

SD: Standard Deviation, AUC : Area under the Plasma-Concentration Curve from Dosing to Last Quantifiable Time Point; $\mathrm{AUC}_{0-\infty}$ : Area under the PlasmaConcentration Curve from Dosing to Infinity; $\mathrm{C}_{\max }$ : Peak Plasma Concentration $\mathrm{T}_{\max }$ : Time to reach Peak Plasma Concentration; $\mathrm{k}_{\mathrm{e}}$ : Elimination Rate Constant; $t_{1 / 2}$ : Half-life

Table 2: Pharmacokinetic parameters of the test Loperamide formulation vs. the reference formulation after oral administration under fasting condition.

shown in Figure 1, both test and reference profiles were superimposable and demonstrated comparable $\mathrm{C}_{\max }$ values. Both formulations reached peak plasma concentrations at approximately $2.0-5.0 \mathrm{~h}$ after administration.

The logarithmic transformed values of $\mathrm{AUC}_{0-\mathrm{t}}(\mathrm{p}=0.28)$ and $\mathrm{AUC}_{0}$ ( $(\mathrm{p}=0.11)$ of both preparations were not significantly different based on ANOVA analysis. However, the logarithmic transformed values of $\mathrm{C}_{\max }(\mathrm{p}=0.037)$ showed a statistically significant difference between the two preparations. For the $\mathrm{T}_{\max }$ value $(\mathrm{p}=0.004)$, there was a statistically significant difference too between two products as shown by Wilcoxon Signed Rank Test.

Bioequivalence can be concluded based on the $90 \%$ confidence interval for the ratio of the $\mathrm{AUC}_{0-\mathrm{t}}, \mathrm{AUC}_{0-\infty}$ and $\mathrm{C}_{\max }$ of the test formulation (Colodium $2 \mathrm{mg}$ capsule) over reference formulation (Imodium $2 \mathrm{mg}$ capsule). In this study, the $90 \%$ confidence interval for the ratio of the $\mathrm{AUC}_{0-\mathrm{t}}, \mathrm{AUC}_{0-\infty}$ and $\mathrm{C}_{\max }$ were calculated to be between $0.8730-1.0181,0.8852-0.9891$ and $0.8023-0.9559$ respectively. All of the values were within the acceptable bioequivalence requirement of $0.8000-1.2500$.

The analysis of the plasma samples was completed within the predetermined one month long term stability period.

The intra-subject coefficient of variation values estimated using the mean square error of the ANOVA analysis for $\mathrm{AUC}_{0-\mathrm{t}}, \mathrm{AUC}_{\mathrm{0- \infty}}$ and $\mathrm{C}_{\max }$ are $17.18 \%, 12.54 \%$ and $17.18 \%$ respectively [7]. Based on these values, the 23 subjects used in the study were found to be sufficient to provide a power $(1-\beta)$ of $80 \%$ to conclude that the two formulations are equivalent where type 1 error $(\alpha)$ is 0.05 [7].

The inter-subject coefficient of variation values for $\mathrm{AUC}_{0-\mathrm{t}}, \mathrm{AUC}_{\mathrm{o- \infty}}$ and $\mathrm{C}_{\max }$ were $50.6 \%, 49.2 \%$ and $38.1 \%$ respectively by estimating the values using the mean square error of the ANOVA analysis.

\section{Tolerability analysis}

There was no drug-related adverse reaction observed or reported throughout the study.

\section{Discussion}

The half-lives (mean, standard deviation) found in this study were also agreeable with the previous literature reports of $11.2(0.8) \mathrm{h}$ [13]. The half-life of test formulation was 12.5 (4.22) $\mathrm{h}$ while the reference formulation was 12.5 (3.87) h. Thus, the washout period determined in this study ( $>5$ half-life) was enough to allow the loperamide concentration in all subjects to fall below the lower limit of bioanalytical quantification before the second phase of the study resumed. 
Citation: Mak WY, Lee YL, Tan SS, Wong JW, Chin SK, et al. (2016) Bioequivalence Study of Two Loperamide Hydrochloride 2 mg Formulations: An Open-Label, Randomized, Single-Dose, Two-Way Crossover Study in Healthy Volunteers under Fasting Conditions. J Bioequiv Availab 8 : 145-148. doi:10.4172/jbb.1000285

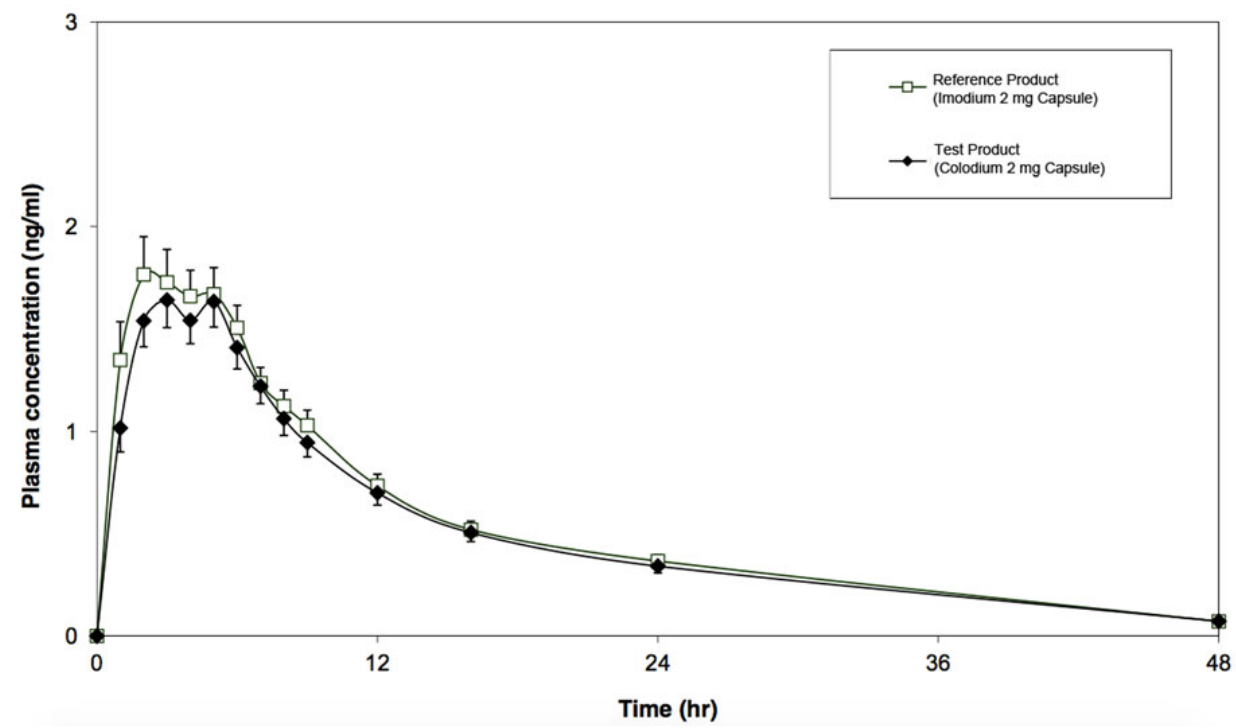

Figure 1: Mean plasma loperamide concentration versus time profiles of both reference formulation (Imodiuym 2 mg Capsule, manufactured by Janssen Cilag S.A., France) and the test formulation (Colodium $2 \mathrm{mg}$ Capsule, manufactured by Hovid Berhad, Perak, Malaysia) after oral administration under fasting condition in healthy volunteers. Mean $\pm \mathrm{SEM}$. $\mathrm{N}=23$

A study by Yu et al. [14] which used the same dose of loperamide $(4 \times$ $2 \mathrm{mg}$ ) was evaluated in 8 healthy male volunteers. The pharmacokinetic values of $\mathrm{C}_{\max }$ were $1.18 \pm 0.37 \mathrm{ng} / \mathrm{ml}, \mathrm{T}_{\max } 5.38 \pm 0.74 \mathrm{~h}$ and half-life $\mathrm{T}_{1 / 2}$ $11.35 \pm 2.06 \mathrm{~h}$. The values were comparable with the pharmacokinetic values of the test products in our study. We obtained pharmacokinetic values (mean, standard deviation) of $\mathrm{C}_{\max } 1.9(0.65) \mathrm{ng} / \mathrm{ml}, \mathrm{T}_{\max } 4.0(1.8)$ $\mathrm{h}$ and half-life $\mathrm{T}_{1 / 2} 12.5(3.87) \mathrm{h} \mathrm{[14]}$.

\section{Conclusion}

This study concludes that the test formulation (Colodium $2 \mathrm{mg}$ capsule) is bioequivalent to the reference formulation (Imodium $2 \mathrm{mg}$ capsule).

\section{Acknowledgement}

The authors would like to thank all the medical staffs at Clinical Research Centre, Hospital Seberang Jaya who have contributed to the study.

\section{Declaration of Personal Interest}

Kah Hay Yuen was the advisor to the R\&D department of Hovid Bhd., the manufacturer of the test formulation. Siew Siew Tan, Jia Woei Wong, Siaw Kuen Chin, Ai Boey Lim and Ean Peng Soon are employees to Attest Research Sdn Bhd, an independent research company. Wen Yao Mak, Yi Lin Lee and Irene Looi did not have any conflict of interest to disclose.

\section{Declaration of Funding Interest}

This study was supported by Hovid Bhd.

\section{References}

1. Baker DE (2007) Loperamide: a pharmacological review. Rev Gastroenterol Disord 7 Suppl 3: S11-18.

2. De Schepper HU, Cremonini F, Park MI, Camilleri M (2004) Opioids and the gut: pharmacology and current clinical experience. Neurogastroenterol Motil 16: $383-394$

3. Musial F, Enck P, Kalveram KT, Erckenbrecht JF (1992) The effect of loperamide on anorectal function in normal healthy men. J Clin Gastroenterol 15: 321-324.

4. Wockhardt UK Ltd. (2015) Loperamide 2mg Hard Capsules - Summary of Product Characteristics (SPC) - (eMC).
5. Jaafar S, Mohd Noh K, Abdul Muttalib K, Othman NH, Healy J (2013) WHOReview of Malaysia healthcare reformation. Asia Pacific Obs Heal Syst Policies 3: 1-102.

6. World Gastroenterology Organisation (2012) Practice guideline for Acute Diarrhea in Adults and Children: A Global Perspective.

7. Diletti E, Hauschke D, Steinijans VW (1992) Sample size determination for bioequivalence assessment by means of confidence intervals. Int $\mathrm{J}$ Clin Pharmacol Ther Toxicol 30 Suppl 1: S51-58

8. Weiner D, in Buncher C, Tsay (Eds) J (1981) Design and analysis of bioavailability studies: In: Statistics in the Pharmaceutical Industry. Marcel Dekker Inc., New York 205.

9. Gibaldi M, Perrier D (1982) Pharmacokinetics, $2^{\text {nd }}$ (Edn) Marcel Dekker, New York 145.

10. Wagner JG (1975) Fundamentals of clinical pharmacokinetics, $1^{\text {st }}$ (Edn) 285

11. Schuirmann DJ (1987) A comparison of the two one-sided tests procedure and the power approach for assessing the equivalence of average bioavailability. $J$ Pharmacokinet Biopharm 15: 657-680.

12. Committee for Medicinal Products for Human Use (2010) EMA Guideline on the Investigation of Bioequivalence. London.

13. Killinger JM, Weintraub HS, Fuller BL (1979) Human pharmacokinetics and comparative bioavailability of loperamide hydrochloride. J Clin Pharmacol 19: 211-218

14. Yu JH, Kim HJ, Lee S, Hwang SJ, Kim W, et al. (2004) LC-MS determination and bioavailability study of loperamide hydrochloride after oral administration of loperamide capsule in human volunteers. J Pharm Biomed Anal 36: 421-427. 